\title{
Synthesis, characterization and thermal degradation of cross-linked polystyrene using the alkyne-functionalized esters as a cross-linker agent by click chemistry method
}

\author{
Hakan Akat ${ }^{1 *}$ and Fehmi Saltan ${ }^{1,2}$ \\ ${ }^{1}$ Department of Chemistry, Faculty of Science, Ege University, Bornova, Izmir, Turkey \\ ${ }^{2}$ Department of Chemistry, Faculty of Science, Çankırı Karatekin University, \\ Merkez, Çankırı, Turkey \\ *hakan.akat@ege.edu.tr
}

\begin{abstract}
In this study, it has been demonstrated that cross-linked polystyrene (CPS) was successfully prepared by using click chemistry. For this purpose, firstly, poly (styrene-co-4 chloromethylstyrene) with 4-chloromethylstyrene was synthesized. Secondly, alkyne-functionalized esters (dipropargyl adipate, dipropargyl succinate) were obtained using propargyl alcohol, adipoyl chloride and succinyl chloride. Azide-functionalized polystrene (PS-N ${ }_{3}$ ) and dipropargyl adipate (or dipropargyl succinate) were reacted in N,N-dimethylformamide for $24 \mathrm{~h}$ at room temperature to give CPS. The synthesized polymer and compounds were characterized by nuclear magnetic resonance $\left({ }^{1} \mathrm{H}-\mathrm{NMR}\right)$, gel permeation chromatography (GPC), fourier transform infrared spectroscopy (FT-IR) and thermogravimetric (TG/DTG) analysis. The surface properties were investigated by Scanning Electron Micrography (SEM).
\end{abstract}

Keywords: polystyrene, cross-linked polymers, click chemistry, thermal degradation.

\section{Introduction}

In last years, polystyrene (PS) has managed to become one of the world's most widely used polymers. PS is one of the three standard plastics (polyolefins, poly(vinyl chloride), and PS), and PS can be applied in many fields, such as the packaging of electrical equipment, apparatus, instruments, and foods, thermal insulation materials for buildings and cold storage, and disposable dinner service ${ }^{[1]}$. However polystyrene do not offer the properties associated with thermoset polymers, and hence its applications are limited. Cross-linking of polystyrene is one approach to improve the properties and consequently to access the demanding regimes of high-tech applications. Crosslinked polystyrene (CPS) have excellent mechanical properties and good chemical stability. Their excellent performances provide wide applications as packing materials for liquid chromatography ${ }^{[2-5]}$, as ion-exchange resins ${ }^{[6,7]}$ and as imprinted adsorbents for the selective separation of hazardous organic compounds ${ }^{[8,9]}$. Cross-linking of PS is readily achieved by the incorporation of a multifunctional monomer during the polymerization process ${ }^{[10-15]}$. High-energy radiation or photochemical irradiation has been used, but in addition to the cross-linking both methods may also involve chain scission that can result in polymer degradation or the introduction of unwanted impurities. Alternative thermal methods for the formulation of thermosetting materials usually involve Diels-Alder and click chemistry reactions which may suffer from the reversibility ${ }^{[16-17]}$. Yagci et al. ${ }^{[15]}$ synthesized polystyrene using click chemistry method. Other methods involves classical cross linker agent as DVB in literature. In our study, we introduce new strategy using both click chemistry method and new crosslinker agents (alkyne-functionalized esters).

\section{Experimental}

\subsection{Materials}

Styrene (S, 99\%, Sigma-Aldrich Company, USA) and 4-chloromethylstyrene (CMS, ca. 60/40 meta/para isomer mixture, 97\%, Sigma-Aldrich Company, USA) were distilled under reduced pressure before use. 2,2 Azobis(isobutyronitrile) (AIBN, 98\%, Sigma-Aldrich Company, USA) was recrystallized from ethanol. Other solvents were purified by conventional procedures. Triethylamine (98\%, Sigma-Aldrich Company, USA) and dichloromethane (99.9\%, HPLC grade, Sigma-Aldrich Company, USA) were distilled from $\mathrm{CaH}_{2}$. Noxyl- free radical (TEMPO, 99\%, Sigma-Aldrich Company, USA) was used as received Ethylenediaminetetraacetic acid (EDTA, 99\%, Sigma-Aldrich Company, USA) N,N-dimethylformamide (DMF 99\%, Sigma-Aldrich Company, USA). Propargyl alcohol (99\%, Sigma-Aldrich Company, USA) were used without any purification. Pyridine (anhydrous, 98\%, Sigma-Aldrich Company, USA). Adipoyl chloride (98\%, Sigma-Aldrich Company, USA). Succinyl chloride (95\%, Sigma-Aldrich Company, USA). 2,2'-bipyridine (reagent plus $>99 \%$, Sigma-Aldrich Company, USA). Copper(I) bromide( $98 \%$, Sigma-Aldrich Company, USA). Hydrochloric acid (ACS reagent, 37\%, Sigma-Aldrich Company, USA).

\subsection{Instrumentation}

${ }^{1} \mathrm{H}-\mathrm{NMR}$ (NMR, nuclear magnetic resonance) measurements were recorded in $\mathrm{CDCl}_{3}$ (deuterium chloroform) with $\mathrm{Si}\left(\mathrm{CH}_{3}\right)_{4}$ as internal standard, using Varian AS-400 (400 MHz) instrument. Fourier transform infrared spectroscopy (FTIR) spectra were recorded on a PerkinElmer FTIR Spectrum 
One-B spectrometer. Molecular weights were determined by gel permeation chromatography (GPC) instrument equipped with a Waters styragel column (HR series 2, 3, 5E) with THF as the eluent at a flow rate of $0.3 \mathrm{~mL} / \mathrm{min}$ and a Waters 410 differential refractometer detector.

TG measurements of powders polymer samples were obtained on PerkinElmer Diamond TA/TGA from 25 to $1000{ }^{\circ} \mathrm{C}$ and heating rate of $10^{\circ} \mathrm{C} /$ min under constant flow rate of $100 \mathrm{~mL} / \mathrm{min}$ of nitrogen atmosphere. The sample weights for all the experiments were taken in the range of 8-10 mg. All SEM images were obtained by using a field emission scanning electron microscope Zeiss FE-SEM Supra 25 microscope under high vacuum at a voltage of $15.0 \mathrm{kV}$ with a working distance of $6.0 \mathrm{~mm}$.

\subsection{Synthesis of poly(styrene-co-chloromethylstyrene)}

Poly(styrene-co-4-chloromethylstyrene) (P(S-co-CMS)) was synthesized as described previously ${ }^{[18]}$.

\subsection{Synthesis of polystyrene azide (PS- $\left.N_{3}\right)^{[19]}$}

A typical procedure for the preparation of PS-N3 from $10 \mathrm{~mol} \% \mathrm{CMS}$ containing $\mathrm{P}(\mathrm{S}-\mathrm{co}-\mathrm{CMS})$ is as follows: $\mathrm{P}(\mathrm{S}-\mathrm{co}-\mathrm{CMS})\left(1.0 \mathrm{~g}, 1.04 \times 10^{-4} \mathrm{~mol}\right)$ was dissolved in DMF, and $\mathrm{NaN}_{3}\left(0.07 \mathrm{~g}, 1.01 \times 10^{-3} \mathrm{~mol}\right)$ was added. The resulting solution was allowed to stir at $25^{\circ} \mathrm{C}$ overnight and precipitated in excess methanol/water mixture ( $1 / 1$ by volume). ${ }^{1} \mathrm{H}$ NMR (CDCl3): $\delta \mathrm{ppm}$ ) 7.40-6.20 (b, 9H), 4.25 (s, 2H) FTIR T\% (cm_1): 3060, 2924, 2096, 1681, 1601, 1492, 1453, 757, 698. Mn: 3500 g/mol PDI: 1.50.

\subsection{Synthesis of dipropargyl adipate (DPA, diprop-2-ynyl adipate) and dipropargyl succinate (DPS, diprop-2-ynyl succinate)}

Propargyl alcohol (2.01 g, $0.036 \mathrm{~mol})$, pyridine (2.69 g, $0.034 \mathrm{~mol})$, and dry dichloromethane $(20 \mathrm{~mL})$ were charged to a $50 \mathrm{~mL}$ round-bottom flask. The resulting solution was maintained at $0{ }^{\circ} \mathrm{C}$ by means of a salt-ice bath. A solution of adipoyl chloride $(2.63 \mathrm{~g}, 0.017 \mathrm{~mol})$ or succinyl chloride $(3.11 \mathrm{~g}, 0.017 \mathrm{~mol})$ in $5 \mathrm{~mL}$ of dry dichloroethane was added dropwise over $30 \mathrm{~min}$. The solution was stirred overnight at room temperature and then transferred to a $250 \mathrm{~mL}$ separatory funnel with the aid of a small amount of dichloromethane. The dichloromethane solution was washed with water $(2 \times 25 \mathrm{~mL}), 5 \% \mathrm{HCl}(20 \mathrm{~mL})$, and saturated sodium bicarbonate solution $(25 \mathrm{~mL})$. The dichloromethane solution was dried over $\mathrm{MgSO}_{4}$ and the mixture was filtered. Organic phase was removed by evaporator. The products were dried under vacuum overnight. DPA: yield of $70 \%$.
FTIR T\% ( $\left.\mathrm{cm}^{-1}\right): 3294(\mathrm{HC} \equiv \mathrm{CH}), 2920\left(-\mathrm{CH}_{2}-\right), 2126$ ( $=\mathrm{C}-\mathrm{H}), 1736$ (-C=O), 1259 (-C-O-) ${ }^{1} \mathrm{H}-\mathrm{NMR}\left(\mathrm{CDCl}_{3}\right.$, $\left.400 \mathrm{MHz}, 25^{\circ} \mathrm{C}, \mathrm{TMS}\right): \delta=1.76\left(\mathrm{~m}, 4 \mathrm{H}, \mathrm{CH}_{2}\right), 2.45(\mathrm{~m}, 4 \mathrm{H}$, $\left.\mathrm{CH}_{2}-\mathrm{CO}\right), 2.55(\mathrm{t}, 2 \mathrm{H}, \equiv \mathrm{C}-\mathrm{H}), 4.72$ (d, 4H, O-CH $)$ ppm. DPS:yield of $65 \%$. FTIR T\% $\left(\mathrm{cm}^{-1}\right): 3289(\mathrm{HC} \equiv \mathrm{CH}), 2920$ $\left(-\mathrm{CH}_{2}-\right), 2128$ ( $\left.=\mathrm{C}-\mathrm{H}\right), 1724(-\mathrm{C}=\mathrm{O}), 1242(-\mathrm{C}-\mathrm{O}-)^{1} \mathrm{H}-\mathrm{NMR}$ $\left(\mathrm{CDCl}_{3}, 400 \mathrm{MHz}, 25^{\circ} \mathrm{C}, \mathrm{TMS}\right): \delta=2.50$ (m, $\left.4 \mathrm{H}, \mathrm{CH}_{2}-\mathrm{CO}\right)$, $4.40\left(\mathrm{~d}, 4 \mathrm{H}, \mathrm{O}-\mathrm{CH}_{2}\right), 2.20(\mathrm{t}, 2 \mathrm{H}, \equiv \mathrm{C}-\mathrm{H})$.

\subsection{Preparation of the crosslinked polystyrene by using $D P A(C-P S A)$ and DPS(C-PSS)}

In a flask, PS-N, DPA (or DPS), copper (I) bromide, 2, 2'-bipyridine and dry DMF were added. The flask was capped with a septum and purged with dry nitrogen for $10 \mathrm{~min}$. The mixture was stirred overnight at room temperature. After removing the catalyst by EDTA, functionalized polymer was precipitated in methanol $(200 \mathrm{~mL})$, filtered, and dried under vacuum overnight with a yield of $70 \%$ (mol feed ratios are seen Table 1).

\section{Result and Discussion}

In our study, we first synthesized (P(S-co-CMS)) and $\mathrm{P}-\mathrm{N}_{3}$. Following experiment was carried out for alkyne-functionalized esters (DPA and DPS). DPA and DPS were used to obtain cross-linked polystyrene. CPS was synthesized via click chemistry (Scheme 1). Chemical structure of both esters and polymers were identified by several techniques such as FT-IR, NMR, GPC, TG, DTG and SEM.

The FT-IR spectra of DPA;PS-N ${ }_{3} ;$ C-PSA $_{65 \%} ; \mathrm{C}-\mathrm{PSA}_{12} \%$ and DPS;PS-N ${ }_{3} ; \mathrm{C}-P S S_{65 \%} ; \mathrm{C}-\mathrm{PSS}_{12 \%}$ are shown in Figure 1 and Figure 2, respectively. According to this FT-IR spectra, appearance of the $-\mathrm{N}_{3}$ stretching is clear at $2096 \mathrm{~cm}^{-1}$ and it is notable that spectra of ADP and DPS show $-\mathrm{HC} \equiv \mathbf{C H}-$; $\equiv \mathbf{C}-\mathbf{H}$ - peaks at around $3290 ; 2120 \mathrm{~cm}^{-1}$. After cross-linked reaction between DPA(or DPS) and PS-N ${ }_{3}$, disappearance of $-\mathrm{N}_{3}$ and alkyne peaks can be seen. These FT-IR data show successful of PS-N $\mathrm{N}_{3}$, CPS, DPA and DPS synthesis. On the other hand, they are also supported by ${ }^{1} \mathrm{H}-\mathrm{NMR}$. From the ${ }^{1} \mathrm{H}$ NMR spectra of synthesized DPA and DPS, it is observed that $-\mathrm{C} \equiv \mathbf{H}$ protons signals at 2.40 and $2.20 \mathrm{ppm}$, respectively. $\mathrm{O}-\mathrm{CH}_{2}$ protons are observed at 4.72(DPA) and 4.40(DPS) ppm. $-\mathrm{CH}_{2}-\mathrm{CO}$ protons can be seen at $2.45 \mathrm{ppm}$ and $2.50 \mathrm{ppm}$.

Thermal behaviour and thermal stability of the synthesized CPS is investigated by TG measurement. TG curves and the corresponding derivative curves (DTG) for cross-linked polystrene are shown in Figure 3 and Figure 4, respectively. The derivative of the thermogram with respect to temperature,

Table 1. Mol feed ratio of synthesized cross-linked polymers.

\begin{tabular}{|c|c|c|c|c|c|}
\hline \multirow{2}{*}{$\begin{array}{c}\text { Compound } \\
\text { (C) }\end{array}$} & \multicolumn{5}{|c|}{$65 \%$ Azide Containing PS } \\
\hline & $\mathrm{CuBr}$ & bipyridine & C & PS-N & DMF \\
\hline DPA & $6.6 \times 10^{-4} \mathrm{~mol} 0.094 \mathrm{~g}$ & $1.3 \times 10^{-3} \mathrm{~mol} 0.2 \mathrm{~g}$ & $4.12 \times 10^{-4} \mathrm{~mol} 0.092 \mathrm{~g}$ & $3.3 \times 10^{-4} \mathrm{~mol} 0.1 \mathrm{~g}$ & $5 \mathrm{ml}$ \\
\hline DPS & $3.3 \times 10^{-4} \mathrm{~mol} 0.0473 \mathrm{~g}$ & $6.6 \times 10^{-4} \mathrm{~mol} 0.10 \mathrm{~g}$ & $2,10 \times 10^{-4} \mathrm{~mol} 0.041 \mathrm{~g}$ & $1.68 \times 10^{-4} \mathrm{~mol} 0.05 \mathrm{~g}$ & $5 \mathrm{ml}$ \\
\hline Compound & \multicolumn{5}{|c|}{$12 \%$ Azide Containing PS } \\
\hline (C) & $\mathrm{CuBr}$ & bipyridine & $\mathrm{C}$ & PS-N & DMF \\
\hline DPA & $0.3 \times 10^{-4} \mathrm{~mol} 0.042 \mathrm{~g}$ & $0.6 \times 10^{-4} \mathrm{~mol} 0.093 \mathrm{~g}$ & $1.87 \times 10^{-4} \mathrm{~mol} 0.041 \mathrm{~g}$ & $1.5 \times 10^{-4} \mathrm{~mol} 0.05 \mathrm{~g}$ & $5 \mathrm{ml}$ \\
\hline DPS & $0.3 \times 10^{-4} \mathrm{~mol} 0.042 \mathrm{~g}$ & $0.6 \times 10^{-4} \mathrm{~mol} 0.093 \mathrm{~g}$ & $1.87 \times 10^{-4} \mathrm{~mol} 0.036 \mathrm{~g}$ & $1.5 \times 10^{-4} \mathrm{~mol} 0.05 \mathrm{~g}$ & $5 \mathrm{ml}$ \\
\hline
\end{tabular}


65
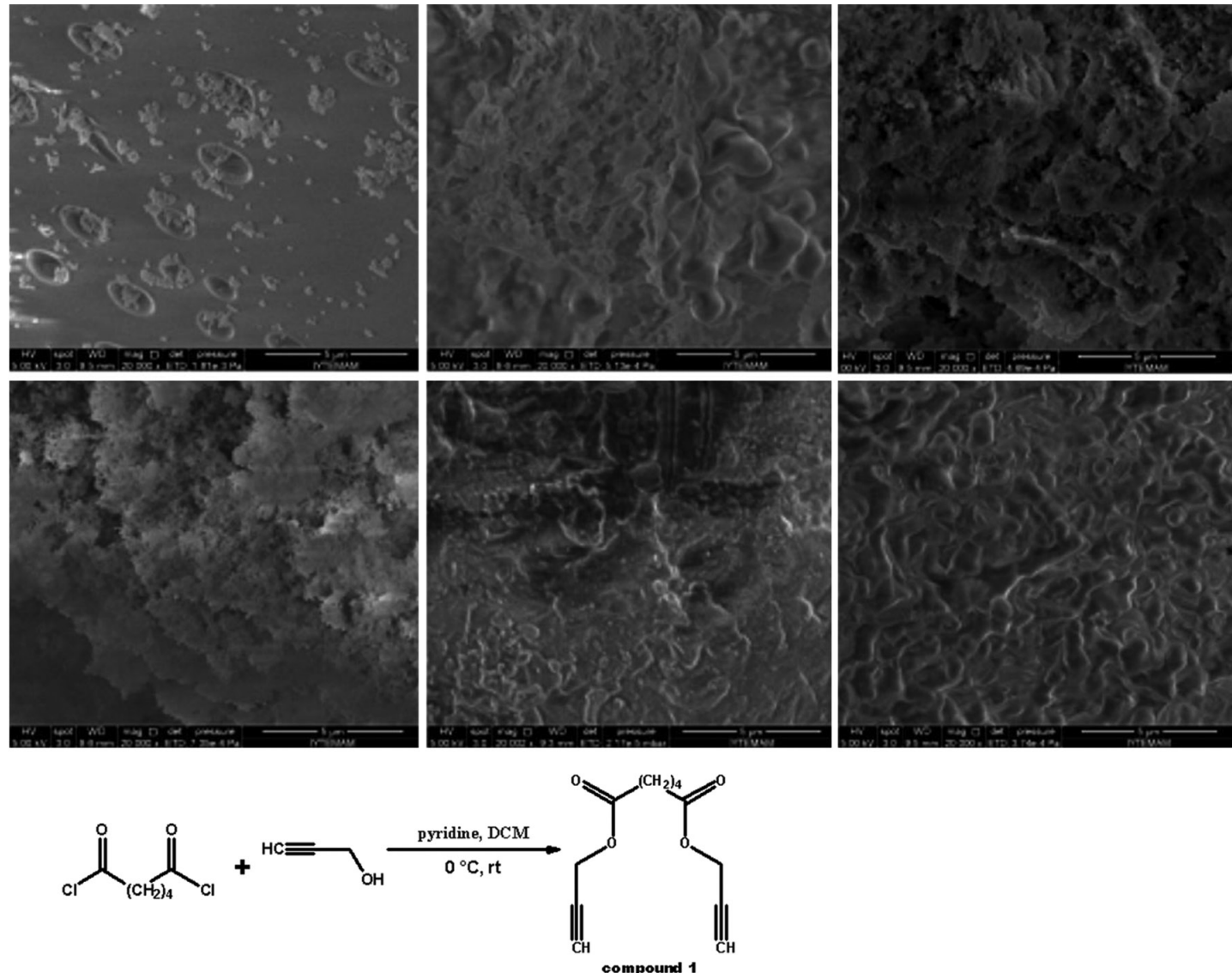

compound 1<smiles>O=C(Cl)CCC(=O)[C-]C#CCO</smiles><smiles>C#CCOC(=O)OCC#C</smiles>

compound 2
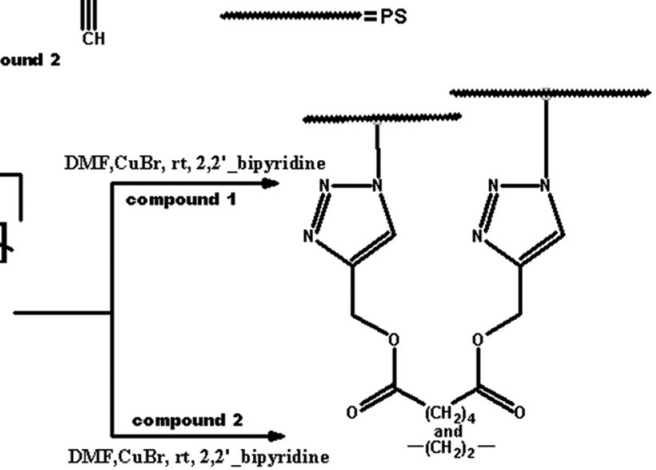

Scheme 1. General procedure for the synthesis of alkyne functionalized ester containing CPS via click chemistry.

also known as a differential thermogram or DTG, indeed shows the maximum rate of polymer decomposition (Tmax). TG thermogram under $\mathrm{N}_{2}$ atmosphere revealed that $\mathrm{C}-\mathrm{PSA}_{65 \%}$ and $\mathrm{C}-\mathrm{PSS}_{65 \%}$ degradation takes place in three stages, C-PSA $12 \%$ and C-PSS ${ }_{12 \%}$ degradation takes place in two stages.

The first stage for the C-PSA $65 \%$ being at a temperature around $312{ }^{\circ} \mathrm{C}$ that corresponds to a very small mass loss of about $10 \%$. The second occurs at about $378{ }^{\circ} \mathrm{C}$ that corresponds to mass loss of about $25 \%$ and the last stage occurs at about $600{ }^{\circ} \mathrm{C}$ that corresponds to mass loss of about $50 \%$. C-PSA ${ }_{12 \%}$ has two main decomposition stages. First one appears to begin around $291{ }^{\circ} \mathrm{C}$ and stop around $414^{\circ} \mathrm{C}$. The second one appears to begin around $390{ }^{\circ} \mathrm{C}$ and stop around $526{ }^{\circ} \mathrm{C}$. The remaining mass without degradation of C-PSA ${ }_{65 \%}$ is higher than C-PSA ${ }_{12 \%}$. When compared to 


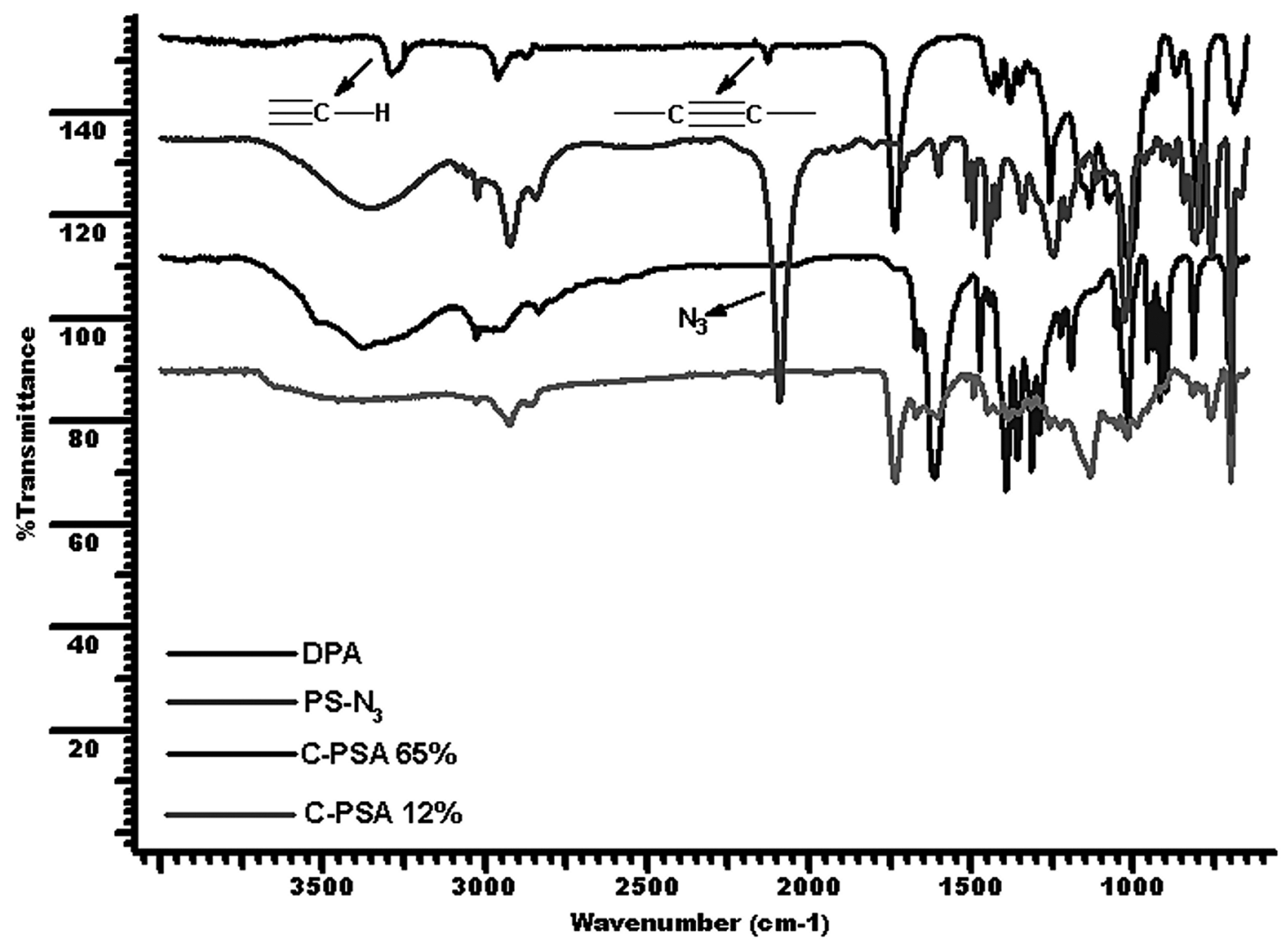

Figure 1. Comparison of FT-IR spectra of DPA;PS-N ${ }_{3} ; \mathrm{C}^{-P S A}{ }_{65} ; \mathrm{C}-\mathrm{PSA}_{12 \%}$.

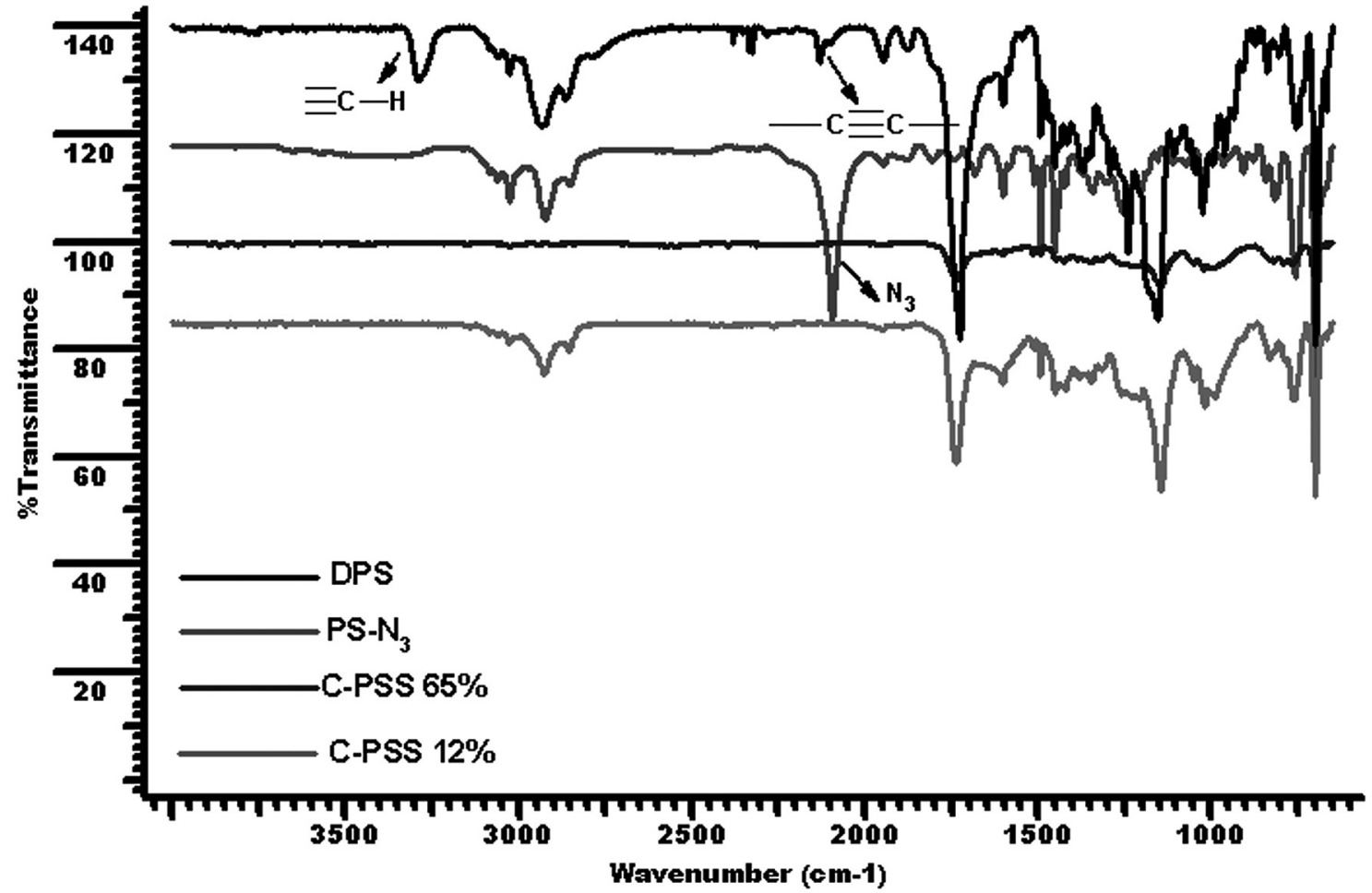

Figure 2. Comparison of FT-IR spectra of DPS;PS-N ${ }_{3} ; \mathrm{C}^{-} \mathrm{PSS}_{65 \%} ; \mathrm{C}-P S S_{12 \%}$. 

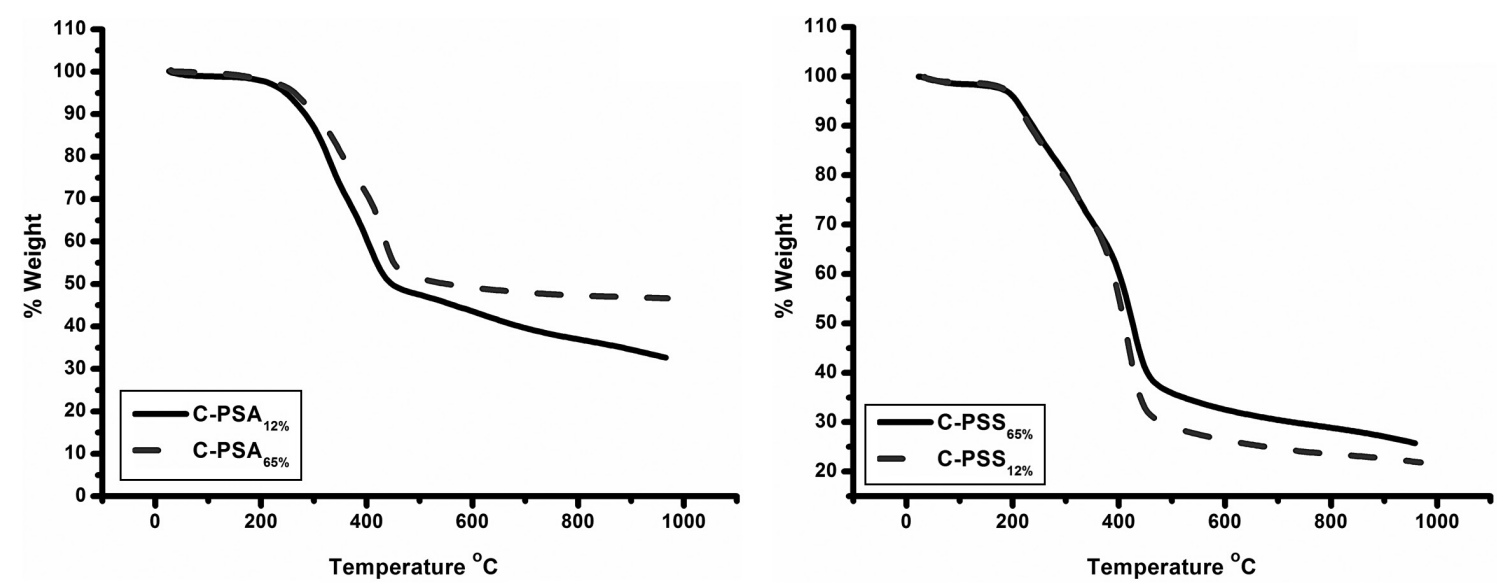

Figure 3. Comparison of TG curves of $\mathrm{PSS}_{65 \%} ; \mathrm{C}-\mathrm{PSS}_{12 \%}$ and C-PSA ${ }_{65 \%} ; \mathrm{C}-\mathrm{PSA}_{12 \%}$.
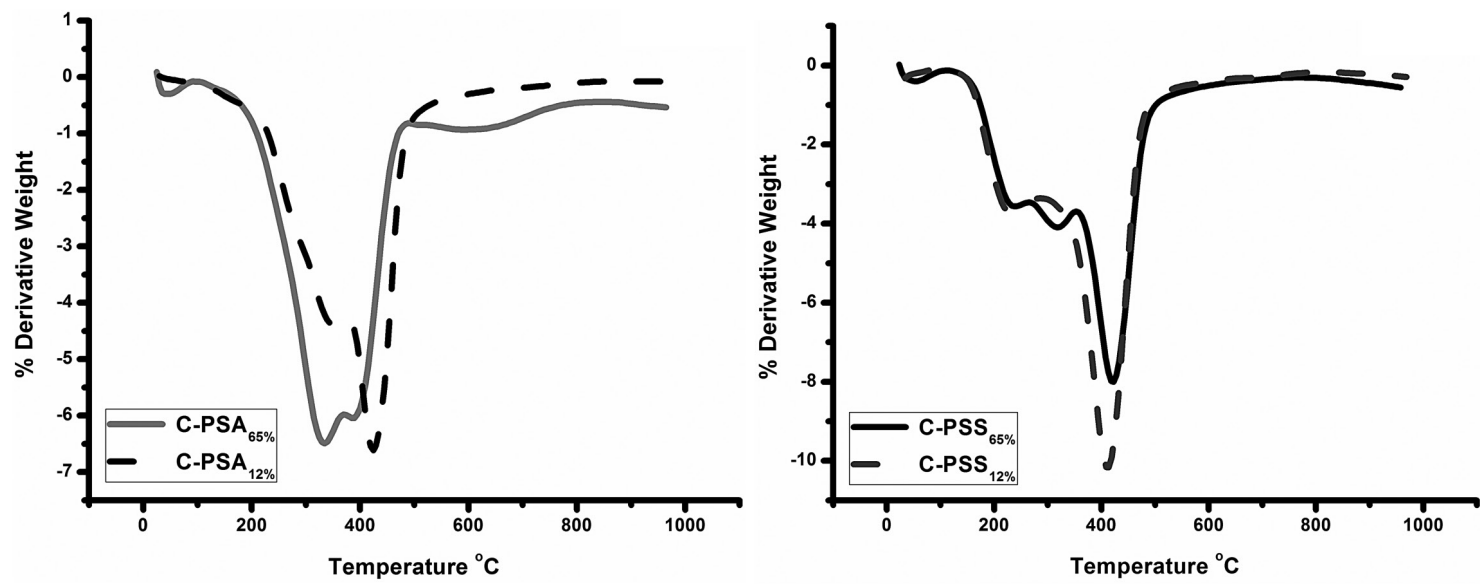

Figure 4. Comparison of DTG curves of C-PSA ${ }_{65 \%} ; \mathrm{C}-\mathrm{PSA}_{12 \%}$ and $\mathrm{PSS}_{65 \%} ; \mathrm{C}^{-} \mathrm{PSS}_{12 \%}$.

C-PSS ${ }_{65 \%}$ and C-PSS ${ }_{12 \%}$, it is observed that C-PSS ${ }_{65 \%}$ more stable then C-PSS ${ }_{12 \%}$.

The first, second and third degradation stages of C-PSS ${ }_{65 \%}$ begin $225,296,396^{\circ} \mathrm{C}$ and the mass loss is about $10 \%, 20 \%$ and $75 \%$, respectively. C-PSS ${ }_{12 \%}$ curves show two degradation stages which temperatures are $220^{\circ} \mathrm{C}$ and $412{ }^{\circ} \mathrm{C}$. When thermal degradation curves of polystyrene compared with crosslinked polystyrene, the char yield of the thermally cured polystyrene was about $40 \%$ and much higher than PS $(0.0 \%)$ in literature ${ }^{[15,20-22]}$. We also observed that thermal stability of CPS increases with the chain length of alkyne functionalized esters used (All Tmax values are shown in Table 2).

Table 3 displays the SEM micrographs obtained before and after cross-linked PS-N $/$ /DPA/DPS. The SEM microphotographs of PS-N $\mathrm{N}_{3}$ show that, most of the microspheres are unregularly spherical, and the interface is clear and smooth. The average particle size is between $1500 \mu \mathrm{m}-680 \mathrm{~nm}$ in diameter. The SEM images of various crosslinked PS, it could be visualized that no inert layer was formed on the surfaces of the C-PSS and C-PSA after cross-linked between PS- $\mathrm{N}_{3}$ and alkyne functionalized esters. The images also indicate an increase in compact
Table 2. Tmax values of the synthesized cross-linked polystyrene.

\begin{tabular}{ccccc}
\hline CPS & \multicolumn{2}{c}{ C-PSS } & \multicolumn{2}{c}{ C-PSA } \\
\hline $\mathrm{N}_{3} \%$ & 12 & 65 & 12 & 65 \\
$\operatorname{Tmax}\left({ }^{\circ} \mathrm{C}\right)$ & 225 & 235 & 351 & 335 \\
& 412 & 320 & 423 & 387 \\
& - & 421 & - & 629 \\
\hline
\end{tabular}

Table 3. SEM micrographs of PS- ${ }_{3}, \mathrm{C}-\mathrm{PSA}_{65 \%} ; \mathrm{C}-\mathrm{PSA}_{12 \%}$ and C-PSS $_{65 \%}-$ C-PSS $_{12 \%}$.

\begin{tabular}{cccc}
\hline \multirow{2}{*}{ Azid\% } & \multirow{2}{*}{$\begin{array}{c}\text { Sem micrographs } \\
\text { of PS-N }\end{array}$} & \multicolumn{2}{c}{$\begin{array}{c}\text { Sem micrographs of CPS after } \\
\text { crosslinked }\end{array}$} \\
\cline { 2 - 3 } & & C-PSA & C-PSS \\
\hline
\end{tabular}

packing with increasing DPA or DPS content, suggesting the formation of a rigid interpenetrating network formation and increased crosslinking.

\section{Conclusions}

In conclusion, we introduce an effective strategy to synthesize a novel cross-linked polystyrene(C-PS) by using click chemistry. The Cross-linking reaction was 
carried out under the condition of low temperature and we used the synthesized alkyne-functionalized esters as a cross-linker. According to data obtained from TG and DTG curves, chain length of alkyne functionalized esters plays important role for thermal stability and in char yield. PS cured in this way exhibited much more thermal stability than those of structurally similar cross-linked polymers. Surface morphologies of CPS changed when used cross-linker (DPA or DPS) of different chain lengths.

\section{References}

1. Ai, Z. Q., Zhou, Q. L., Guang, R., \& Zhang, H. T. (2005) Preparation and properties of polystyrene- $g$-poly(butyl acrylate) copolymer emulsions with ultrasonic radiation. I. Preparation technology and coagulum ratio. Journal of Applied Polymer Science, 96(4), 1405-1409. http://dx.doi.org/10.1002/app.21571.

2. Qin, L., He, X. W., Zhang, W., Li, W. Y., \& Zhang, Y. K. (2009). Surface-modified polystyrene beads as photografting imprinted polymer matrix for chromatographic separation of proteins. Journal of Chromatography. A, 1216(5), 807-814. http://dx.doi. org/10.1016/j.chroma.2008.12.007. PMid:19111313.

3. Yu, P., Li, X., Li, X., Lu, X., Ma, G., \& Su, Z. (2007). Preparative purification of polyethylene glycol derivatives with polystyrene-divinylbenzene beads as chromatographic packing. Bioorganic \& Medicinal Chemistry Letters, 17(20), 5605-5609. http://dx.doi.org/10.1016/j.bmcl.2007.07.094. PMid:17822896.

4. Mizutani, A., Nagase, K., Kikuchi, A., Kanazawa, H., Akiyama, Y., Kobayashi, J., Annaka, M., \& Okano, T. (2010). Thermoresponsive polymer brush-grafted porous polystyrene beads for all-aqueous chromatography. Journal of Chromatography. A, 1217(4), 522-529. http://dx.doi.org/10.1016/j.chroma.2009.11.073. PMid:20015506.

5. Zhang, X., Shen, S., \& Fan, L. (2007). Studies progress of preparation, properties and applications of hyper-cross-linked polystyrene networks. Journal of Materials Science, 42(18), 7621-7629. http://dx.doi.org/10.1007/s10853-007-1763-y.

6. Belfer, S., \& Glozman, R. (1979). Anion exchange resins prepared from polystyrene crosslinked via a Friedel-Crafts reaction. Journal of Applied Polymer Science, 24(10), 21472157. http://dx.doi.org/10.1002/app.1979.070241007.

7. Jun, B. H., Byun, J. W., Kim, J. Y., Kang, H., Park, H. J., Yoon, J., \& Lee, Y. S. J. (2010). Facile method of preparing silver-embedded polymer beads and their antibacterial effect. Journal of Materials Science, 45(11), 3106-3108. http://dx.doi. org/10.1007/s 10853-010-4345-3.

8. Yun, Y. H., Shon, H. K., \& Yoon, S. D. (2009). Preparation and characterization of molecularly imprinted polymers for the selective separation of 2,4-dichlorophenoxyacetic acid. Journal of Materials Science, 44(22), 6206-6211. http://dx.doi. org/10.1007/s10853-009-3863-3.

9. Yu, H., Cai, Z., Liu, X., Li, M., Shi, Z., \& Cui, Z. (2014). Crosslinked polystyrene beads modified with polar groups for the separation of aromatic/aliphatic hydrocarbons. Journal of Applied Polymer Science, 131(8), 40156-40162. http://dx.doi. org/10.1002/app.40156.
10. Archibald, T. G., Malik, A. A., Baum, K., \& Unroe, M. R. (1991). Thermally stable acetylenic adamantane polymers. Macromolecules, 24(19), 5261-5265. http://dx.doi.org/10.1021/ ma00019a005.

11. Bellenger, V., Verdu, J., \& Morel, E. (1989). Structure-properties relationships for densely cross-linked epoxide-amine systems based on epoxide or amine mixtures. Journal of Materials Science, 24(1), 63-68. http://dx.doi.org/10.1007/BF00660933.

12. Douglas, W. E., \& Overend, A. S. (1991). Curing reactions in acetylene terminated resins-I. Uncatalyzed cure of arylpropargyl ether terminated monomers. European Polymer Journal, 27(11), 1279-1287. http://dx.doi.org/10.1016/00143057(91)90066-W.

13. Kirchhoff, R. A., Bruza, K., Carriere, C., \& Rondan, N. (1992). Makromolekulare Chemie. Macromolecular Symposia, 5455(1), 531-534. http://dx.doi.org/10.1002/masy.19920540140.

14. Morel, E., Bellenger, V., Bocquet, M., \& Verdu, J. (1989). Structure-properties relationships for densely cross-linked epoxide-amine systems based on epoxide or amine mixtures. Journal of Materials Science, 24(1), 69-75. http://dx.doi. org/10.1007/BF00660934.

15. Yagci, Y., Kiskan, B., Gacal, B., \& Ergin, M. (2007). Thermally curable polystyrene via click chemistry. Macromolecules, 40(13), 4724-4727. http://dx.doi.org/10.1021/ma070549j.

16. Wang, Y. X., \& Ishida, H. (1999). Cationic ring-opening polymerization of benzoxazines. Polymer, 40(16), 4563-4570. http://dx.doi.org/10.1016/S0032-3861(99)00074-9.

17. Kasapoglu, F., Cianga, I., Yagci, Y., \& Takeichi, T. (2003). Photoinitiated cationic polymerization of monofunctional benzoxazine. Journal of Polymer Science. Part A, Polymer Chemistry, 41(21), 3320-3328. http://dx.doi.org/10.1002/ pola.10913.

18. Gacal, B., Akat, H., Balta, D. K., Arsu, N., \& Yagci, Y. (2008). Synthesis and characterization of polymeric thioxanthone photoinitatiors via double click reactions. Macromolecules, 41(7), 2401-2405. http://dx.doi.org/10.1021/ma702502h.

19. Yildirim, Y., Dogan, B., Muğlali, S., Saltan, F., Ozkan, M., \& Akat, H. (2012). Synthesis, characterization, and thermal degradation kinetic of polystyrene- $g$-polycaprolactone. Journal of Applied Polymer Science, 126(4), 1236-1246. http://dx.doi. org/10.1002/app.36888.

20. Malhotra, S. L., Hesse, J., \& Blanchard, L. P. (1975). Thermal decomposition of polystyrene. Polymer, 16(2), 81-93. http:// dx.doi.org/10.1016/0032-3861(75)90133-0.

21. Sivalingam, G., \& Madras, G. (2003). Thermal degradation of poly (\&-caprolactone). Polymer Degradation \& Stability, 80(1), 11-16. http://dx.doi.org/10.1016/S0141-3910(02)00376-2.

22. McNeill, I. C., Zulfiqar, M., \& Kousar, T. A. (1990). Detailed investigation of the products of the thermal degradation of polystyrene. Polymer Degradation \& Stability, 28(2), 131151. http://dx.doi.org/10.1016/0141-3910(90)90002-O.

Received: Oct. 03, 2014

Revised: Feb. 26, 2015

Accepted: Mar. 20, 2015 